Research article

\title{
Predictive value of quantitative diffusion-weighted imaging and 18-F-FDG- PET in head and neck squamous cell carcinoma treated by (chemo) radiotherapy
} \author{
Pim de Graaf ${ }^{a}$, Ronald Boellaard ${ }^{\mathrm{a}}$, Jonas A. Castelijns ${ }^{\mathrm{a}}$ \\ ${ }^{\text {a }}$ Department of Radiology and Nuclear Medicine, VU University Medical Center, Amsterdam, the Netherlands \\ ${ }^{\mathrm{b}}$ Department of Epidemiology and Biostatistics, the Netherlands \\ ${ }^{\mathrm{c}}$ Department of Radiation Oncology, VU University Medical Center, Amsterdam, the Netherlands \\ ${ }^{\mathrm{d}}$ Department of Otolaryngology - Head and Neck Surgery, VU University Medical Center, Amsterdam, the Netherlands \\ ${ }^{\mathrm{e}}$ Department of Head and Neck Surgical Oncology, University Medical Center Utrecht, Utrecht, the Netherlands
}

Roland M. Martens ${ }^{\mathrm{a}, *}$, Daniel P. Noij ${ }^{\mathrm{a}}$, Thomas Koopman ${ }^{\mathrm{a}}$, Ben Zwezerijnen ${ }^{\mathrm{a}}$, Martijn Heymans ${ }^{\mathrm{b}}$, Marcus C. de Jong ${ }^{\mathrm{a}}$, Otto S. Hoekstra ${ }^{\mathrm{a}}$, Marije R. Vergeer ${ }^{\mathrm{c}}$, Remco de Bree ${ }^{\mathrm{d}, \mathrm{e}}$, C. René Leemans ${ }^{\mathrm{d}}$,

\section{A R T I C L E I N F O}

\section{Keywords:}

Head and neck

Squamous cell carcinoma

DWI

MRI

PET

Prognosis

\begin{abstract}
A B S T R A C T
Background and purpose: In head and neck squamous cell carcinoma (HNSCC) (chemo)radiotherapy is increasingly used to preserve organ functionality. The purpose of this study was to identify predictive pretreatment DWI- and ${ }^{18}$ F-FDG-PET/CT-parameters for treatment failure (TF), locoregional recurrence (LR) and death in HNSCC patients treated by (chemo)radiotherapy.

Materials and methods: We retrospectively included 134 histologically proven HNSCC patients treated with (chemo)radiotherapy between 2012-2017. In 58 patients pre-treatment DWI and ${ }^{18} \mathrm{~F}$-FDG-PET/CT were performed, in 31 patients DWI only and in 45 patients ${ }^{18}$ F-FDG-PET/CT only. Primary tumor (PT) and largest lymph node $\left({ }_{\mathrm{LN}}\right)$ metastasis were quantitatively assessed for TF, LR and death. Multivariate analysis was performed for ${ }^{18}$ F-FDG-PET/CT and DWI separately and thereafter combined. In patients with both imaging modalities, positive and negative predictive value in TF and differences in LR and death, were assessed.

Results: Mean follow-up was 25.6 months (interquartile-range; 14.0-37.1 months). Predictors of treatment failure, corrected for TNM-stage and HPV-status, were $\mathrm{SUV}_{\max -\mathrm{PT}}, \mathrm{ADC}_{\mathrm{max}-\mathrm{PT} \text {, total lesion glycolysis }(\mathrm{TLG}} \mathrm{-LN}_{\text {) }}$, $\mathrm{ADCp}_{-\mathrm{LN}}\left(\mathrm{P}=0.049, \mathrm{P}=0.024, \mathrm{P}=0.031, \mathrm{P}=0.047\right.$, respectively). $\mathrm{TLG}_{-\mathrm{PT}}$ was predictive for $\mathrm{LR}$ $(\mathrm{P}=0.003)$. Metabolic active tumor volume $\left(\mathrm{MATV}_{-\mathrm{PT}}\right)(\mathrm{P}=0.003), \mathrm{ADC}_{\mathrm{GTV}-\mathrm{PT}}(\mathrm{P}<0.001), \mathrm{ADCSD}$ $(\mathrm{P}=0.048)$ were significant predictors for death. In patients with both imaging modalities $\mathrm{SUV}_{\text {max-PT }}$ remained predictive for treatment failure $(P=0.049)$, TLG-LN for $L R(P=0.003)$ and $A_{-D_{G T V} P \mathrm{P}}$ for death $(\mathrm{P}<0.001)$. Higher predictive value for treatment failure was found for the combination of $S_{\text {max-PT }}$ and $A D C_{\text {max-PT, }}$, compared to either one separately.

Conclusion: Both DWI- and ${ }^{18}$ F-FDG-PET/CT-parameters appear to have predictive value for treatment failure, locoregional recurrence and death. Combining $\mathrm{SUV}_{\text {max-PT }}$ and $\mathrm{ADC}_{\max -\mathrm{PT}}$ resulted in better prediction of treatment failure compared to single parameter assessment.
\end{abstract}

\section{Introduction}

Head and neck squamous cell carcinoma (HNSCC) is the most common head and neck malignancy with 550,000 cases annually worldwide [1]. Most patients presenting with locally advanced disease are treated with (chemo)radiotherapy in the context of organ preservation. Complete response cannot be achieved in approximately $25-30 \%$ [1]. Surgical salvage treatment can be difficult and functional

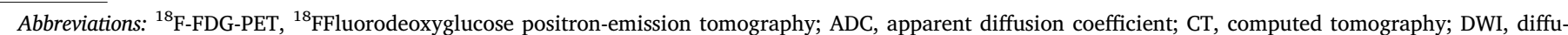

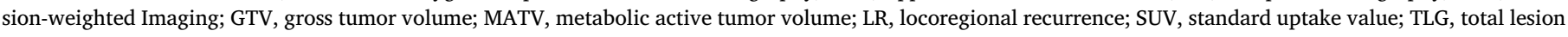
glycolysis; TF, treatment failure

* Corresponding author: Department of Radiology and Nuclear Medicine, VU University Medical Center, PO Box 7057, 1007, MB, Amsterdam, the Netherlands.

E-mail address: ro.martens@vumc.nl (R.M. Martens).
} 
outcome may be uncertain [2]. It is essential to identify tumor characteristics predictive of response to (chemo)radiotherapy to increase treatment efficacy and long-term outcome by treatment intensification or by offering alternative treatment options as early as possible to these patients (e.g. surgery or best supportive care).

Besides clinical and histopathological factors [3], imaging parameters may provide important prognostic biomarkers [4,5]. Functional imaging, such as diffusion-weighted imaging (DWI) and ${ }^{18}$ F-Fluorodeoxyglucose positron-emission computer tomography $\left({ }^{18} \mathrm{~F}\right.$-FDG-PET/ CT), could provide additional information on pathophysiology $[6,7]$. DWI measures cell density and diffusion capacity, which can be quantified with the apparent diffusion coefficient (ADC). Low ADC values are associated with hypercellular tissues (e.g. malignant tumors) $[6,8,9]$. Tumors with high ADC values have a poor prognosis, possibly due to the high stromal content of the tumor [10]. ${ }^{18}$ F-FDG uptake on PET/CT can be quantified by the standardized uptake value (SUV) [11]. High FDG uptake was found in aggressive tumoral phenotypes and associated with active proliferation [9], invasion and immunohistochemical biomarkers (e.g. hypoxia-inducible HIF-1 $\alpha$, low anti-apoptotic Bcl-2, apoptotic regulator p53, and tumor growth Ki-67, p16INK4a as marker for HPV) [9,12-14].

Tumor characteristics associated with treatment failure or adverse long-term survival, might be identified with functional imaging $[5,7,15,16]$. Qualitative assessment is inadequate to measure tumor heterogeneity and often carries a certain extent of subjectivity, resulting in high interobserver variability. Quantitative analysis could provide more reproducible information of tumor heterogeneity by utilizing whole lesion assessment [17,18].

Earlier studies showed that (combinations of) DWI and ${ }^{18}$ F-FDGPET/CT predict treatment response [15] and long-term survival [5]. However, most of these studies included only small patient populations without correction for TNM-stage, HPV-status, tumor volume or location. Furthermore, they used different image acquisition systems, which resulted in limited robustness of predictive and prognostic value [5,16,19-21]. Although some studies use histogram analysis, the predictive accuracy of the combination of DWI and ${ }^{18}$ F-FDG-PET/CT for primary tumor and lymph node metastasis was not investigated $[20,21]$. Finally, quantification of based on robust whole-lesion delineation by multiple independent observers, including partial volume correction [22], was not performed previously [5,16,20,21]. The purpose of this study was to identify predictive pretreatment DWI- and ${ }^{18} \mathrm{~F}$ FDG-PET/CT-parameters for treatment failure, locoregional recurrence and death in a large cohort of HNSCC-patients treated with (chemo) radiotherapy.

\section{Methods}

\subsection{Patients}

We retrospectively enrolled 134 consecutive patients treated from 2012-2017. The local ethics committee waived informed consent. This study was reported according to the STARD-criteria [23]. Inclusion criteria were: histopathologically proven HNSCC of primary tumor with or without lymph node metastasis; pretreatment DWI and/or ${ }^{18} \mathrm{~F}$-FDGPET/CT and planned (chemo)radiotherapy. Exclusion criteria were: previous locoregional treatment for HNSCC and insufficient image quality for lesion segmentation.

Treatment failure was defined as: presence of residual malignant tissue within the first 6 months post-treatment. For the assessment of treatment failure we used a standardized physical examination and imaging with MRI and PET-CT which was performed between 3-6 months after treatment.

Locoregional recurrence (LR) was defined as presence of a locoregional (primary tumor ${ }_{\mathrm{PT}}$ ) or lymph node $\left({ }_{\mathrm{LN}}\right)$ ) recurrence in the total follow-up period after end of treatment. In case of suspected malignancy on imaging, histological confirmation was acquired.
Death was defined as the time patients were alive after end of treatment. Patients were censored at the date of the last follow-up for surviving patients.

\subsection{MRI acquisitions}

MR imaging was performed using a 1.5 T MR system (Signa HDxt, GE Healthcare, Milwaukee, WI) with a 12-channel neurovascular headand-neck-array coil. The protocol consisted of at least conventional T1weighted Spin-Echo (SE), short-tau-inversion-recovery (STIR) and echoplanar imaging (EPI)-DWI with TR/TE: 4300-5600/59-98 ms; inversion time $160 \mathrm{~ms}$, averages: 3; parallel imaging acceleration factor: 2; acquisition time ranged between 235 and $314 \mathrm{~s}$; flip-angle: $90^{\circ}$; matrix size: $256 \times 256$ (which was not directly acquired, but zero filled from an acquisition matrix of $86 \times 128$ ), voxel size $1 \times 1 \times 4 \mathrm{~mm}^{3}, 21-28$ slices. ADC was measured using $2 \mathrm{~b}$-values ( 0 and $1000 \mathrm{~s} / \mathrm{mm} 2)$. The ADC values of patients with a TE of 59 and $98 \mathrm{~ms}$ were not significantly different $(p=0.46)$, and therefore both patient groups were combined in the analysis.

\section{3. ${ }^{18}$ F-FDG-PET/CT acquisitions}

${ }^{18}$ F-FDG-PET/low-dose-CT was performed according the EANM guidelines 2.0 on a Gemini TOF-64 PET/CT (Philips Medical Systems, Best, The Netherlands) with EARL accreditation [24]. Low-dose noncontrast CT $(120 \mathrm{kV} ; 50 \mathrm{mAs})$ was used for attenuation correction and anatomic correlation of ${ }^{18} \mathrm{~F}$-FDG uptake. Whole-body ${ }^{18} \mathrm{~F}$-FDG-PET/CT was performed in arms-down-position, with $18 \mathrm{~cm}$ axial field of view, from mid-thigh to skull vertex, $60 \mathrm{~min}$ after intravenous administration of $2.5 \mathrm{M} \mathrm{Bq} / \mathrm{kg}{ }^{18} \mathrm{~F}$-FDG, $2 \mathrm{~min}$ per bed-position. The ${ }^{18} \mathrm{~F}$-FDG-PET images were reconstructed using vendor-provided and EARL-compliant reconstruction protocol with photon-attenuation correction. Reconstructed images had an image matrix size of $144 \times 144$ and voxel size of $4 \times 4 \times 4 \mathrm{~mm}$. Post-reconstruction image resolution was $7 \mathrm{~mm}$ full-width at half maximum.

\subsection{Image analysis}

Delineation on MRI was performed manually by two independent radiologists with 34 and 10 years of experience in head-and-neck radiology, respectively. Whole-tumor segmentation was performed, including necrotic or cystic areas and excluding voxels, which were filled with air or subject to distortion. ${ }^{18} \mathrm{~F}$-FDG-PET/CT semi-automated delineations (Fig. 1), based on a background-corrected 50\% of SUVpeak isocontour [25], were assessed and corrected by a resident supervised by a nuclear medicine physician with 5 and 30 years of experience in head-and-neck PET, respectively. Observers were aware of the HNSCC diagnosis, TNM-stage (7th edition) and primary tumor location for delineation of proven malignant lesions. Any discrepancies between the observers were resolved by performing a segmentation in consensus.

Whole-lesion segmentation was performed on MRI on the T1- and ADC-map in accordance with other sequences (Fig. 1) using VelocityTM software (Varian Medical Systems, Inc, Palo Alto, USA). Histograms were generated with Matlab (MathWorks Inc, MA, USA), based on included voxels. The following MRI parameters were extracted: gross tumor volume on $\mathrm{T} 1\left(\mathrm{~T}_{\mathrm{GTV}}\right)$ and $\mathrm{ADC}\left(\mathrm{ADC}_{\mathrm{GTV}}\right), \mathrm{ADC}_{\text {mean }}, \mathrm{ADC}_{\text {max }}$, $\mathrm{ADC}_{\min }, \mathrm{ADC}$ standard deviation $\left(\mathrm{ADC}_{\mathrm{SD}}\right), \mathrm{ADC}$ percentiles $\left(\mathrm{ADCp}_{10}\right.$ to $\mathrm{ADCp} 90$; indicating the value below which a given percentage of tumor voxels in a group of voxels fall), $\mathrm{ADC}_{\text {kurtosis, }}$, and $\mathrm{ADC}_{\text {skewness }}$. Consensus values were used for final analyses.

With ${ }^{18}$ F-FDG-PET/CT, segmentation was performed using a background-corrected $50 \%$ isocontour of tumor SUV $_{\text {peak }}$ [26]. SUV was normalized to body weight. $\mathrm{SUV}_{\text {peak }}$ was defined as the highest uptake in $1 \mathrm{~mL}$ spherical volume of interest across all tumor voxel locations. Uptake parameters were derived using in-house developed Accurate software, [24] to quantify lesions on ${ }^{18}$ F-FDG-PET/CT were: 


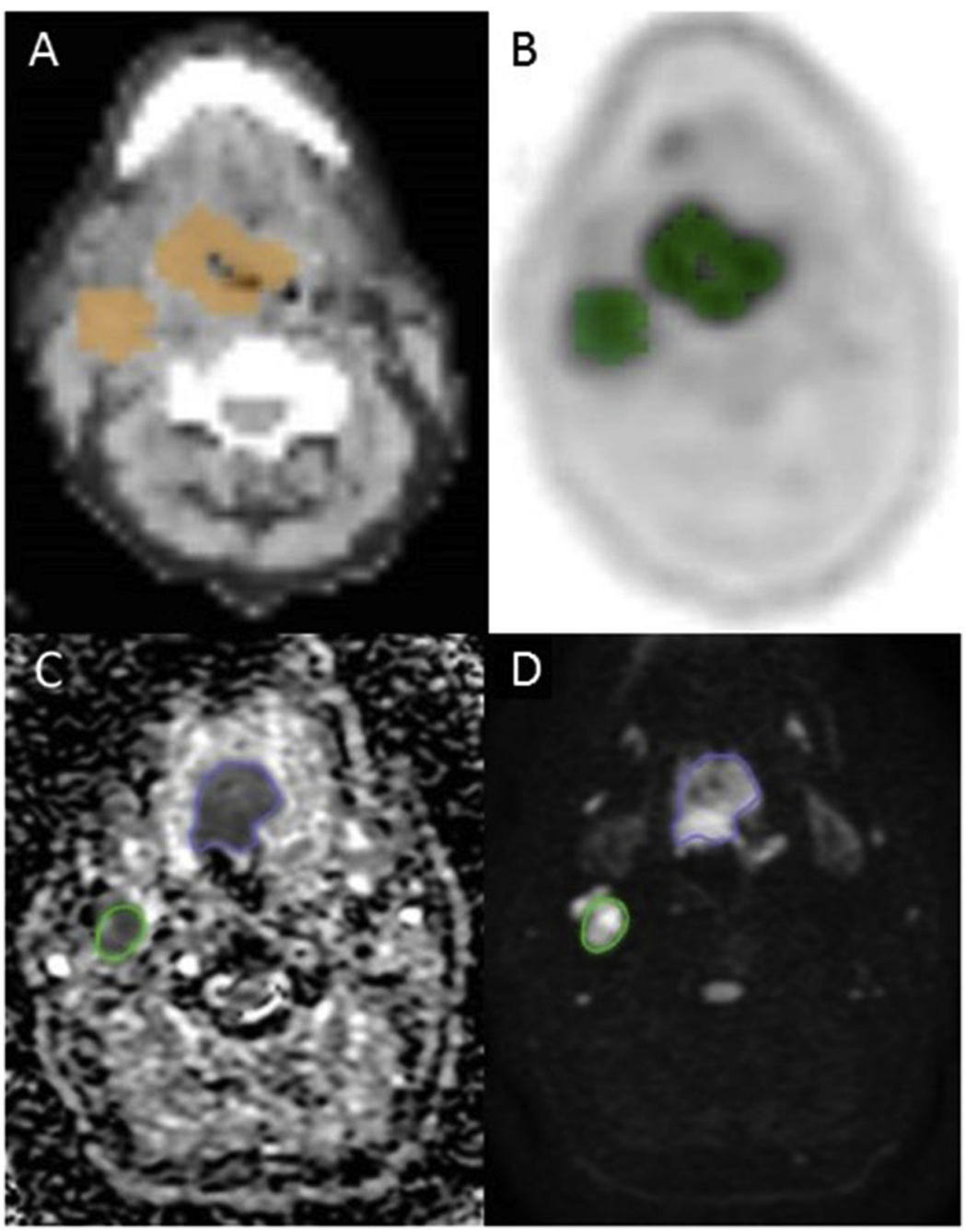

Fig. 1. Primary tumor delineated on the right base of the tongue and largest lymph node metastasis on the B) ${ }^{18}$ F-FDG-PET image (green) in accordance with the anatomical reference of A) the CT image (orange). On the ADC-map C) an area of low intensity and on the b-1000 map (D) of high intensity (diffusion restriction).

metabolically active tumor volume (MATV), $\mathrm{SUV}_{\text {max }}, \mathrm{SUV}_{\text {peak }}, \mathrm{SUV}_{\text {mean }}$. Total lesion glycolysis (TLG) was calculated by the tumor volume multiplied by the SUV mean of the included voxels [17].

\subsection{Statistical analysis}

The correlation of functional parameters between DWI and ${ }^{18} \mathrm{~F}-\mathrm{FDG}$ $\mathrm{PET} / \mathrm{CT}$ was assessed using the Pearson $\mathrm{r}$ test. The difference and correlation of functional parameters between HPV-positive and HPV-negative patients was analyzed performing the Pearson $r$ test. Logistic regression was used to predict locoregional treatment failure. We used Cox regression model to assess locoregional recurrence (LR) and death. $P$-values of $<0.05$ were considered statistically significant in the univariate analysis. Significant single modality parameters were combined in multivariate analysis, for DWI and ${ }^{18}$ F-FDG-PET/CT separately, using a backward Wald test (Fig. 2). The remaining significant parameters for DWI or ${ }^{18}$ F-FDG-PET/CT, for tumor and for lymph node metastasis were taken together, corrected for TNM-stage and HPV status. This correction was performed by adding T-, N- and HPV-status to the multivariate analysis. Multivariable regression analysis was performed according to the TRIPOD-statement, accepting $p$-values up to 0.157 to enhance the model applicability to other patient groups [27]. For survival analyses, the end of treatment was used as start of follow-up. For multivariate analysis only patients were included of whom all data was available (i.e. DWI and ${ }^{18}$ F-FDG-PET/CT). Subgroup analyses was performed for tumors with a MATV > $4.2 \mathrm{ml}$ [22], to avoid bias from partial volume effect in small tumors.

With receiver operating characteristic (ROC) analysis three optimal cut-offs (three highest Youden indices (YI)) of significant multivariate parameters were determined to predict treatment failure. The positive and negative predictive value (post-test risk and 1-post-test risk, respectively) at each cut-off value was calculated for treatment failure using a prevalence ranging from 10 to $50 \%$. A log-rank test of remaining significant multivariable parameters (divided by the optimal cut-off) was presented as Kaplan Meier survival curves. Analyses were performed using SPSS (version 18.0; SPSS Inc., Chicago, III, USA).

\section{Results}

\subsection{Patients characteristics}

The study population consisted of 134 patients ( 97 males, mean age; 64.7 years, range $41-91$ years; Table 1 ). Fifty-eight patients underwent both DWI and ${ }^{18}$ F-FDG PET/CT (mean interval 6 days, range 0-13 days; mean interval before treatment initiation was 16 days, range 7-25 days), 31 patients underwent DWI only, 45 patients ${ }^{18} \mathrm{~F}$-FDG-PET/CT only (Fig. 2). All 134 patients completed radiotherapy with $70 \mathrm{~Gy}$ in total, of which 18 accelerated radiotherapy. Eighty-seven patients $(58.2 \%)$ received concomitant cisplatin and 18 patients received concomitant cetuximab. 


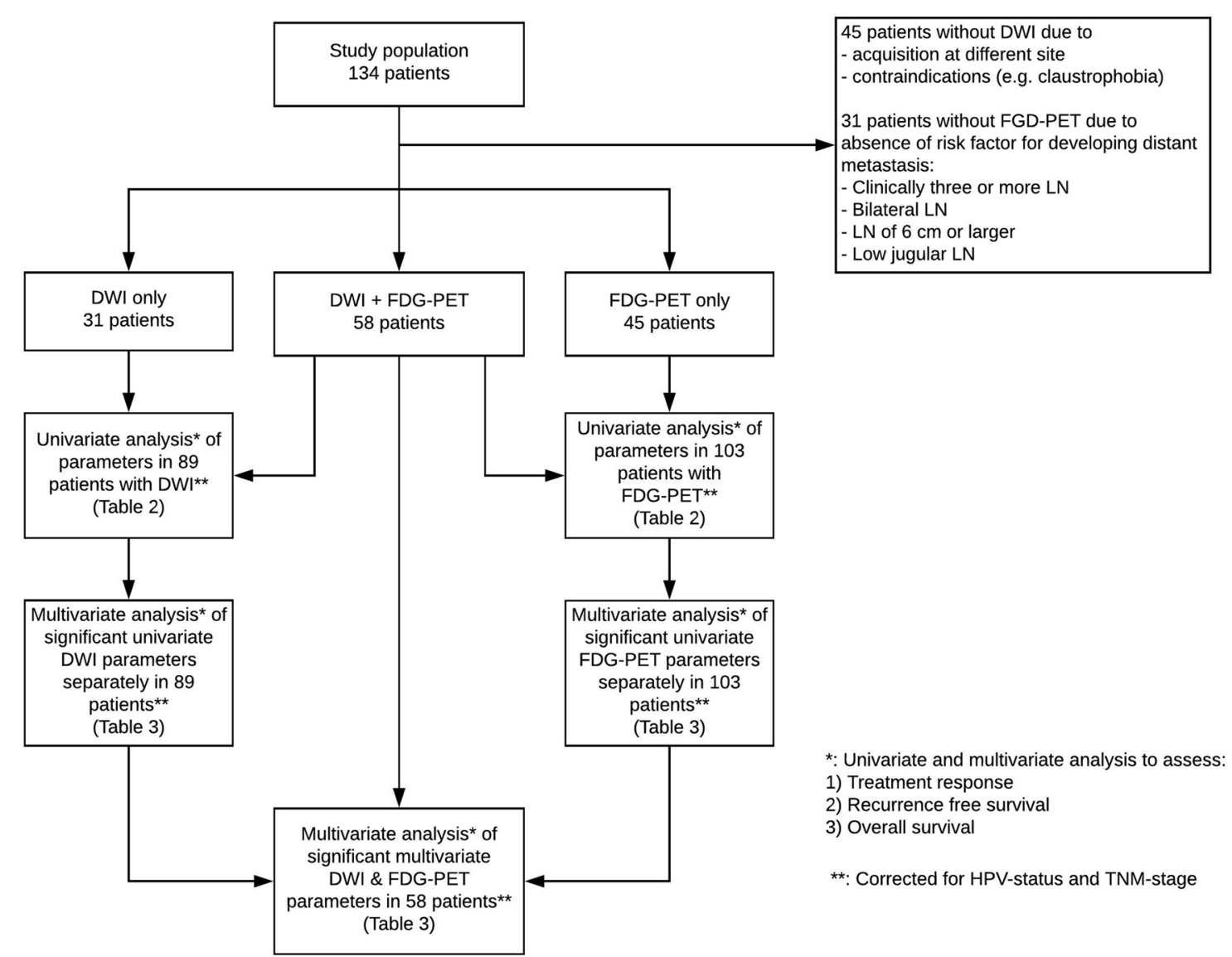

Fig. 2. Flowchart of study population with single or combination of imaging acquisitions.

The median follow-up of patients without treatment failure or locoregional recurrence (LR) was 25.6 months (interquartile range; 16.3-37.8 months).

In seventeen (12.7\%) a locoregional treatment failure occurred during the maximum follow-up time of 6 months after treatment, which percentage was approximately similar in the DWI only and ${ }^{18}$ F-FDGPET/CT only group (16 versus 15 patients $(11.9 \%$, $11.1 \%$, respectively).

During the total follow-up time, in 28 patients (20.9\%) a locoregional recurrence (LR) occurred. The LR rate in both DWI only and ${ }^{18}$ F-FDG-PET/CT only group was also similar (27 versus 28 patients (20.1\%, 20.9\%, respectively).

Furthermore, 42 patients $(31.3 \%)$ died during the total follow-up time, which was also approximately similar in both DWI only and ${ }^{18} \mathrm{~F}$ FDG-PET/CT only group (40 versus $42(29.8 \%, 32.1 \%$, respectively).

\subsection{Correlations of functional imaging and HPV status}

The primary tumor ADCGTV and ADCkurtosis were found significantly correlated (supplement 1 and 2) with all PET-parameters (range Pearson $r$ from 0.42-0.91, $\mathrm{p}<0.0015$ after Bonferroni's correction for multiple testing). In lymph node metastases, only ADCGTV correlated significantly with TLG $(r=0.51, \mathrm{p}<0.0015)$.

Forty-seven patients were found HPV-positive, $67 \mathrm{HPV}$-negative and in 20 patients HPV-status was unknown. In the treatment failure group; 5 patients were HPV-positive, 8 HPV-negative, 4 unknown. The LR group consisted of $8 \mathrm{HPV}$-positive, 16 HPV-negative, 4 unknown status. The patients who died, consisted of $7 \mathrm{HPV}$-positive, $30 \mathrm{HPV}$-negative, 5 unknown.

For primary tumor 18F-FDG-PET/CT parameters (MATV, SUV max $_{\text {, }}$ $\left.\mathrm{SUV}_{\text {peak, }} \mathrm{SUV}_{\text {mean }}, \mathrm{TLG}\right)$ and $\mathrm{ADC}$-parameters $\left(\mathrm{ADC}_{\text {mean }}, \mathrm{ADC}_{\mathrm{SD}}\right.$,
$\left.\mathrm{ADC}_{\text {min }}, \mathrm{ADC}_{\text {max }}, \mathrm{ADC}_{\text {percentiles }}\right)$ mean values were significant different ( $\mathrm{p}<0.05$ ) between HPV-negative and HPV-positive tumours (Table 2). A low-to-moderate correlation with HPV-status was found for $\mathrm{ADC}_{\text {mean-PT }}(\mathrm{r}=0.452, \mathrm{P}<0.01), \mathrm{ADC}_{\text {max-PT }}(\mathrm{r}=0.319, \mathrm{P}=0.002)$, $\mathrm{ADC}_{\mathrm{p} 10-\mathrm{PT}}$ to $\mathrm{ADC}_{\mathrm{p} 90-\mathrm{PT}} \quad(\mathrm{r}=0.4-0.48, \quad \mathrm{P}<0.01), \quad \mathrm{SUV}_{\text {peak-PT }}$ $(\mathrm{r}=0.326, \mathrm{P}<0.01)$, SUV $_{\text {mean-PT }}(\mathrm{r}=0.325, \mathrm{P}<0.01)$.

\subsection{Image and univariate analysis of treatment failure}

In the treatment failure group, a wider distribution (higher $\mathrm{ADC}_{\mathrm{SD}}$ ) and higher $\mathrm{ADC}$ of voxels (higher $\mathrm{ADC}_{\text {max }}$ ) in $\mathrm{PT}$ was shown (Fig. $3 \mathrm{~A}$ ).

Univariate DWI ( $\mathrm{ADC}_{\text {max }}$ PT and ADCSD-PT) and all primary tumor ${ }^{18} \mathrm{~F}$-FDG-PET/CT parameters were higher in patients with treatment failure (Table 3, Fig. 4). However, subgroup analysis (not tabulated) of tumors with MATV larger than $4.2 \mathrm{ml}$ (to minimize partial volume effects; $n=79$ patients), did not result in any significant ${ }^{18}$ F-FDG-PET predictor.

\subsection{Image and univariate analysis of $L R$ and death}

A significant higher $\mathrm{ADC}_{\mathrm{p} 70-\mathrm{PT}}$ and $\mathrm{ADC}_{\mathrm{p} 80-\mathrm{PT}}$ was shown in $\mathrm{LR}$ (Fig. 3B). A higher $\mathrm{ADC}_{\mathrm{SD}-\mathrm{PT}}$ and $\mathrm{ADC}_{\text {max-PT }}$ was found in patients who died (Fig. 3C).

The evaluation of LR showed that MATV $-\mathrm{PT}(\mathrm{P}=0.001)$ and TLG-PT $(\mathrm{P}=0.003)$ were higher in LR (Table 3$)$. The prediction of death resulted in a significant predictive value for MATV $(P<0.001), \operatorname{SUV}_{\text {peak }}(\mathrm{P}=0.025)$, $\operatorname{SUV}_{\text {mean }}(\mathrm{P}=0.039)$, TLG $(\mathrm{P}=0.001), \mathrm{ADC}_{\mathrm{GTV}}(\mathrm{P}<0.001), \mathrm{ADCSD}$ $(P=0.031)$ and $\mathrm{ADC}_{\max }(\mathrm{P}=0.007)$. Subgroup analysis of tumors (not tabulated) with MATV larger than $4.2 \mathrm{ml}(\mathrm{n}=79$ patients) resulted for $\mathrm{LR}$ and death a predictive value of MATV $_{-\mathrm{PT}}$ (LR: $\mathrm{P}=0.001$, death: $\mathrm{P}<0.001$ ) and TLG.PT (LR: $\mathrm{P}=0.003$, death: $\mathrm{P}=0.001$ ). 
Table 1

Patient characteristics.

\begin{tabular}{|c|c|}
\hline Patient characteristics & \\
\hline Total patients & 134 \\
\hline \multicolumn{2}{|l|}{ Gender } \\
\hline Male & 97 \\
\hline Female & 37 \\
\hline \multicolumn{2}{|l|}{ Age } \\
\hline Mean age & 66.4 \\
\hline Range & $41.0-90.1$ \\
\hline \multicolumn{2}{|l|}{ Site } \\
\hline Oral cavity & 3 \\
\hline Oropharynx & 96 \\
\hline Hypopharynx & 24 \\
\hline Larynx & 11 \\
\hline \multicolumn{2}{|l|}{ TNM } \\
\hline $\mathrm{T} 1$ & 16 \\
\hline $\mathrm{T} 2$ & 44 \\
\hline T3 & 33 \\
\hline $\mathrm{T} 4$ & 41 \\
\hline No & 20 \\
\hline N1 & 25 \\
\hline N2 & 88 \\
\hline N3 & 1 \\
\hline M1 & 0 \\
\hline \multicolumn{2}{|l|}{ HPV status } \\
\hline Positive & 47 \\
\hline Negative & 67 \\
\hline Unknown & 20 \\
\hline \multicolumn{2}{|l|}{ Treatment } \\
\hline Radiotherapy & 134 \\
\hline Chemotherapy total & 105 \\
\hline Cisplatin & 87 \\
\hline Cetuximab & 18 \\
\hline \multicolumn{2}{|l|}{ Outcome } \\
\hline Treatment failures" & 17 \\
\hline (HPV + / - / unknown) & $5 / 8 / 4$ \\
\hline Locoregional recurrences & 28 \\
\hline (HPV + / - / unknown) & $8 / 16 / 4$ \\
\hline Deaths & 42 \\
\hline (HPV + / - / unknown) & $7 / 30 / 5$ \\
\hline
\end{tabular}

* Treatment failures within 6 months follow-up after end of treatment.

** Locoregional recurrences within the total follow-up time after end of treatment.

\subsection{Multivariate analysis of treatment failure}

The significant univariate parameters (Table 3) predicting treatment failure, were assessed in a multivariate analysis for DWI and ${ }^{18} \mathrm{~F}$-FDGPET/CT separately, and for PT and LN separately (Table 4), corrected for TNM-stage and HPV-status. Primary tumor $\mathrm{SUV}_{\text {max-PT }}(\mathrm{P}=0.049)$ and $\mathrm{ADC}_{\text {max-PT }}(\mathrm{P}=0.024)$, and $\mathrm{TLG}_{-\mathrm{LN}}(\mathrm{P}=0.031)$ and $\mathrm{ADC}_{\mathrm{p} 20-\mathrm{LN}}$ $(P=0.047)$ were significant predictors of treatment failure.

Finally, a head-to-head comparison was made in patients $(n=58)$ who underwent both imaging modalities using these remaining significant parameters (Table 4), which revealed $\mathrm{SUV}_{\text {max-PT }}$ as significant predictive factor $(\mathrm{P}=0.042)$ in multivariate analysis with a hazard ratio of 1.302 (95\%CI 1.010-1.679). Subgroup analysis of tumors with a MATV larger than $4.2 \mathrm{ml}(\mathrm{PT} \mathrm{n}=48, \mathrm{LN} \mathrm{n}=26)$, resulted in the same predictive parameter (not tabulated).

In order to determine the additional value of predicting treatment failure using a combination of both modalities, the remaining PT and LN significant multivariate parameters of both cohorts (ADC max $_{\text {ax }}$ of DWIcohort and $\mathrm{SUV}_{\max }$ of ${ }^{18} \mathrm{~F}$-FDG-PET/CT-cohort) were analysed in patients with MATV $>4.2 \mathrm{ml}$ in order to minimize partial volume effects (Table 5). First, optimal cut-offs for SUV $_{\text {max-PT }}$ were 7.13, 11.3, 13.58; and for $\mathrm{ADC}_{\max }$ were $1.927,2.236,2.528$, respectively. The positive predictive value (PPV) and negative predictive value (NPV) were calculated for $\mathrm{ADC}_{\max }$ and $\mathrm{SUV}_{\max }$ at the cut-off values described above, showing additional value of combining $\mathrm{ADC}_{\max }$ and $\mathrm{SUV}_{\max }$. For each assumed prevalence, the PPV for treatment failure was the highest when both a high $\mathrm{ADC}_{\text {max }}(>2.528)$ and high $\operatorname{SUV}_{\max }(>13.58)$ were assessed. Regardless of the $\mathrm{ADC}_{\max }$, a SUV $\mathrm{SUx}_{\max }<7.13$ ruled out treatment failure. For each prevalence, the NPV for treatment failure increased as lower $\mathrm{SUV}_{\max }$ cut-off and $\mathrm{ADC}_{\max }$ cut-off value was used. The combination of significant multivariate nodal parameters $\mathrm{ADC}_{\mathrm{p} 20-\mathrm{LN}}$ and $\mathrm{TLG}_{-\mathrm{LN}}$ resulted in a slightly better prediction of treatment failure (Supplement 3).

\subsection{Multivariate analysis of $L R$ and death}

The significant univariate parameters for LR prediction, were assessed per modality in a multivariate analysis, corrected for TNM-stage and HPV-status. This resulted in only TLG-PT as significant $(\mathrm{P}=0.003)$ prognostic ${ }^{18} \mathrm{~F}$-FDG-PET/CT parameter or LR (single modality and modalities together, Table 4). TLG PT $_{\text {T }}$ remained significant Subgroup analysis (MATV $>4.2 \mathrm{ml}$, not tabulated) resulted in TLG.PT $(\mathrm{P}=0.039)$ as predictive parameter for LR. Performing the ROC analysis, an optimal cut-off value for TLG PT $_{\text {PT }}$ of 36.2 was found which use was significant predictive for LR (Fig. 5A).

The univariate parameters for prognosis of death of ${ }^{18}$ F-FDG-PET/

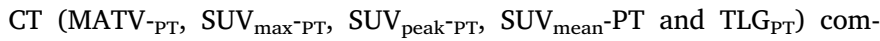
bined in a multivariate analysis, resulted in $\mathrm{MATV}_{-\mathrm{PT}}(\mathrm{P}=0.003)$ as remaining significant prognosticator (single modality, Table 4).

In univariate significant $\mathrm{DWI}$ parameters for death $\left(\mathrm{ADC}_{\mathrm{GTV}^{-\mathrm{PT}}}\right.$, $\mathrm{ADC}_{\mathrm{SD}-\mathrm{PT}}$ and $\mathrm{ADC}_{\text {max-PT}}$ ) were combined in a multivariate analysis resulted in $\mathrm{ADC}_{\mathrm{GTV}-\mathrm{PT}}(\mathrm{P}<0.001)$ and $\mathrm{ADC}_{\mathrm{SD}-\mathrm{PT}}(\mathrm{P}=0.048)$ as significant prognosticators (single modality, Table 4). ADC $_{\mathrm{GTV}-\mathrm{PT}}$ $(\mathrm{P}=0.009)$ remained a significant predictor in subgroup analysis (MATV $>4.2 \mathrm{ml}$ ) who underwent both imaging modalities (not tabulated).

The combination of significant prognosticators to predict death resulted in only $\mathrm{ADC}_{\mathrm{GTV}}{ }^{-\mathrm{PT}}$ as significant prognosticator (Modalities together, Table 4; $\mathrm{P}<0.001$ ). The use of both $\mathrm{MATV}_{-\mathrm{PT}}$ and $\mathrm{ADC}_{\mathrm{GTV}-\mathrm{PT}}$ (Fig. 5C) resulted in a similar overall survival curve as for single parameter assessment (Fig. 5B), which showed no additional value for the use of both modalities for the prediction of death.

\section{Discussion}

Pretreatment DWI and ${ }^{18}$ F-FDG-PET/CT were evaluated for their predictive value for treatment failure, locoregional recurrence-free survival and overall survival. The assessment of both SUV $_{\text {max-PT }}$ and $\mathrm{ADC}_{\text {max-PT }}$ showed additional value for treatment failure prediction, compared with single parameter assessment. Furthermore, a high TLG. PT was predictive for locoregional recurrence, and high MATV $_{-\mathrm{PT}}$, $\mathrm{ADC}_{\mathrm{GTV}-\mathrm{PT}}$, and $\mathrm{ADC}_{\mathrm{SD}-\mathrm{PT}}$ were predictive for death.

In order to identify tumor characteristics with quantitative analyses, whole-lesion delineation could capture tumor heterogeneity and ignores subjective exclusion of necrosis or other potential predictive characteristics [20,28,29]. This characteristic and possible predictive heterogeneity may be caused by areas with high cellularity, necrosis, stroma and areas with increased or decreased vascularity. The mean value of an imaging parameter may be sub-optimal, because when areas with low and high ADC values are included in the ROI, heterogeneity is flattened out.

Tumor heterogeneity (Fig. 1b) may be depicted by ADC histogram analysis $[20,30]$.

A wide distribution, as sign of lesion heterogeneity, might be reflected by the $\mathrm{ADC}_{\mathrm{SD}}$ [30]. Furthermore, low-cellular tumor parts (e.g. necrosis) might be measured with high $\mathrm{ADC}$ values (high $\mathrm{ADC}_{\max }$ or ADC-percentiles), while high-cellular solid viable areas are reflected by low $\mathrm{ADC}$ values. In our study primary tumor $\mathrm{ADC}_{\mathrm{SD}}$ and $\mathrm{ADC}_{\max }$ parameters were higher in non-responders, which might be due to limited efficacy of radiotherapy in structures with a low cellularity (e.g. low diffusion restriction such as necrosis and fibrosis) [31]. Moreover, 
Table 2

Differences and correlation of functional parameters divided per HPV-status in PT and LN. Most functional parameters were significant higher (marked green) in HPV negative patients.

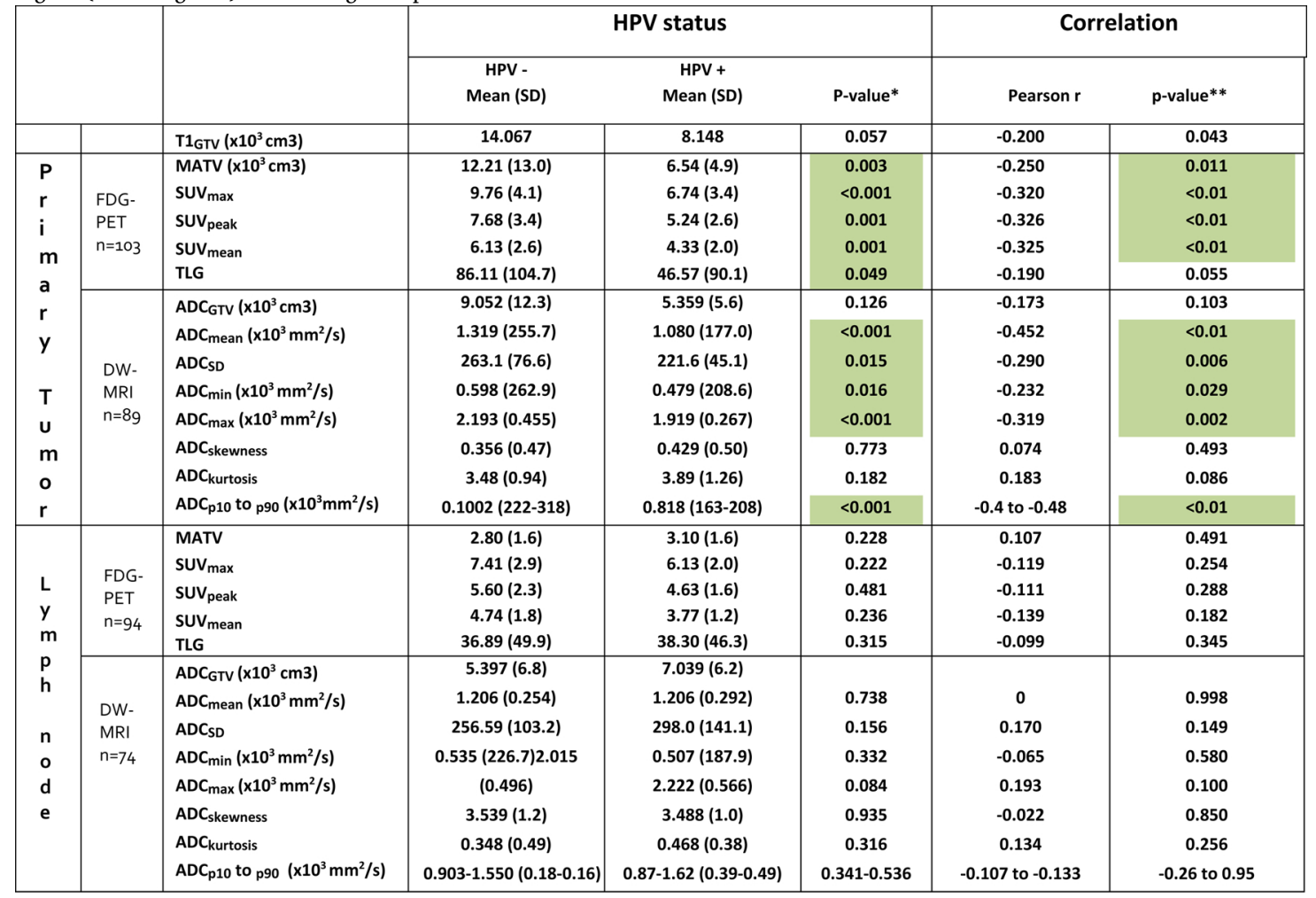

SD: Standard deviation.

*: Difference between HPV-positive and HPV-negative tumours (Mann-Whitney U test).

**: Correlation between a high functional parameter value and a positive HPV-status (Pearson $\mathrm{r}$ test).
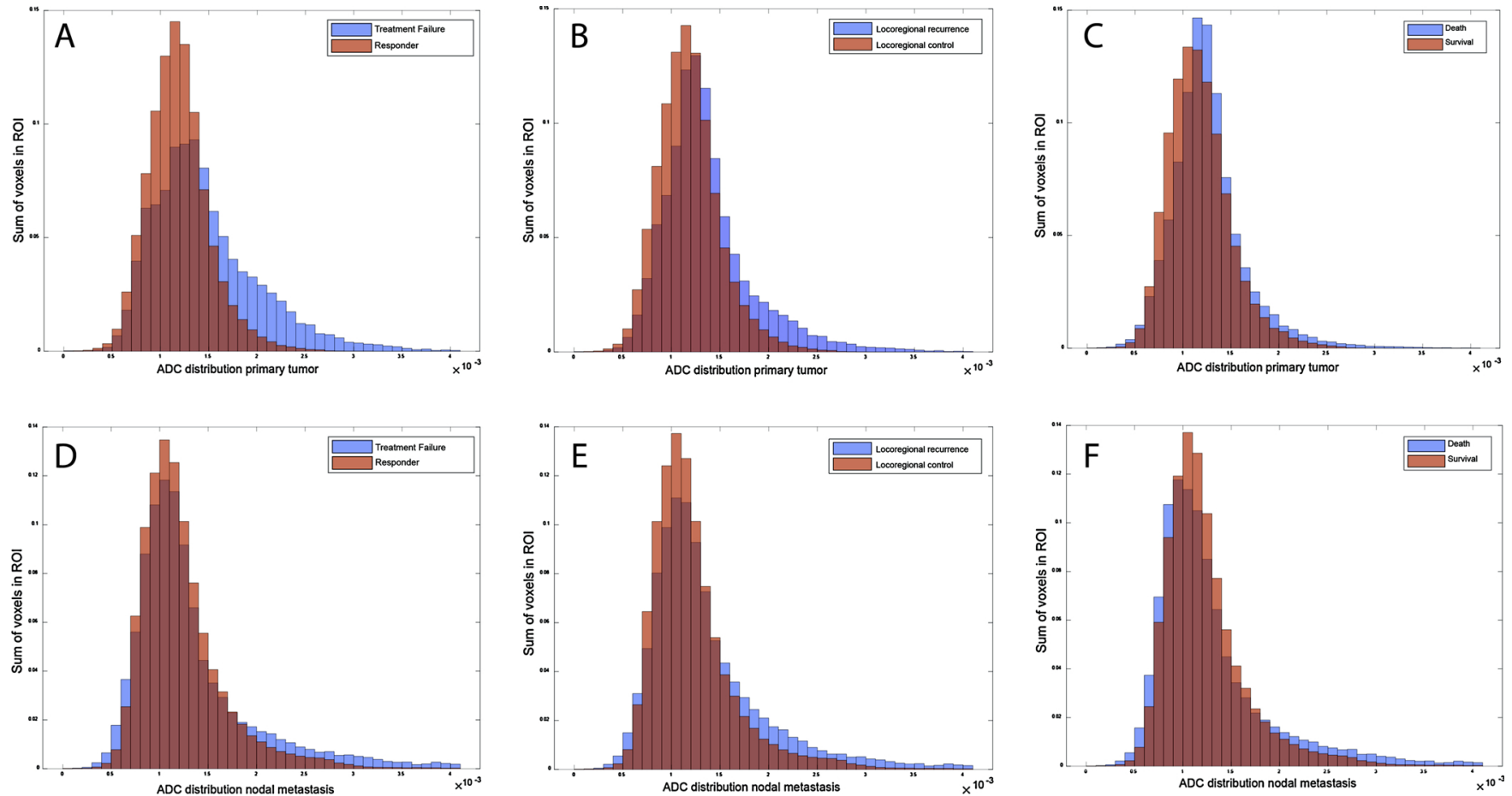

Fig. 3. Histogram of ADC voxels of primary tumors (PT) and lymph node metastases (LN) with adverse (blue) and good outcome (orange). A) In treatment failures $(\mathrm{TF})$, wider distribution $\left(\mathrm{ADC}_{\mathrm{SD}}\right.$ ) and higher $\mathrm{ADC}_{\max }$ values was found compared to the responders. $\mathrm{B}$ ) Locoregional recurrences showed a significant higher $\mathrm{ADC}$ max PT. C) Patients who died showed a wider distribution and higher $\mathrm{ADC}_{\text {max-PT. }}$ D) TF included more of the lowest ADC.LN voxels. E) LR showed a higher LN peak and a less wide distribution in the control group. $\mathrm{F}$ ) The $\mathrm{ADC}_{\text {-LN }}$ parameters showed no significant predictors for death. 
Table 3

Univariate parameters of FDG-PET and DWI separately for predicting treatment failure, locoregional failure and death. The odds ratio for treatment failure and hazard ratios for locoregional recurrence and death is shown. The significant univariate parameters were assessed in a multivariate analysis (Table 4).

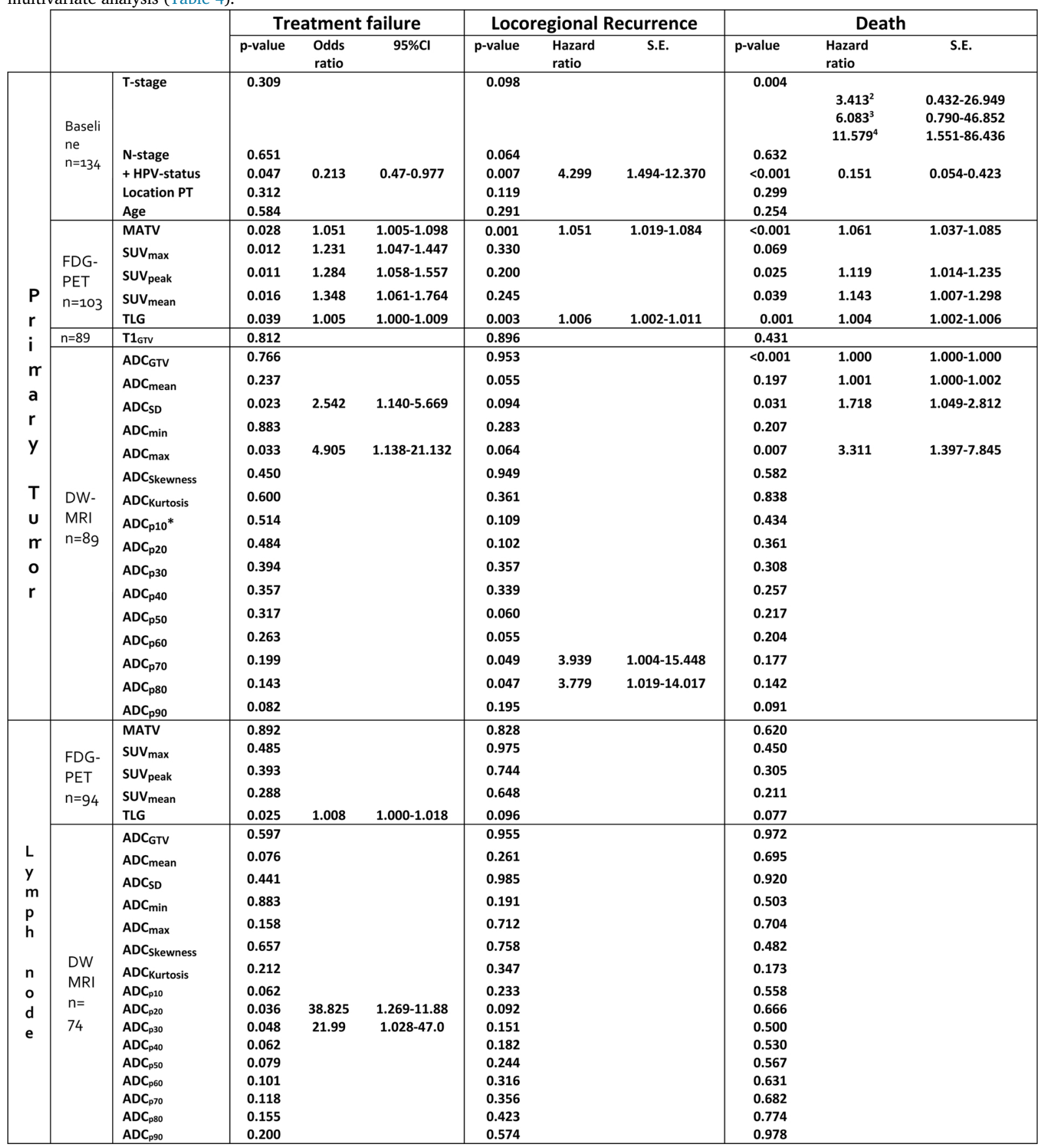

1,2,3,4 : T-stage Color green: Significant univariate parameter S.E: Standard error *: ADC-percentiles.

in this study primary tumor $\mathrm{ADC}_{\mathrm{GTV}}$ and $\mathrm{ADC}_{\text {kurtosis }}$ significantly correlated with all FDG-PET parameters, which implies a volume dependency in all FDG-PET parameters as well as $\mathrm{ADC}_{\text {kurtosis }}$ as a possible surrogate marker for FDG uptake. Last, lymph node $\mathrm{ADC}_{\mathrm{p} 20-\mathrm{LN}}$ was found higher in non-responders, which might be caused by necrotic parts, insufficient vascularization and keratin protein contents [19,32].

HPV-negative tumors were correlated with high ADC-values $(r=0.452)$. This is in line with some previous studies [28,33-35], in which higher ADC histogram parameters in HPV-negative patients were found. This was confirmed by Meyer et al. [36], who found a negative correlation of high $\mathrm{ADC}_{\max }$ and $\mathrm{ADC}_{\mathrm{SD}}$ with low P53 expression in HPVnegative tumors, which lead to minimal cell cycle arrest, senescence or apoptosis [37]. This was attributed to a more keratinizing morphology with variable cellularity, cell shape, keratin pearls, large intratumoral necrosis, hemorrhage and stromal cells found in HPV-negative tumors $[28,31,33]$. However, 2 studies did not find any differences of ADC histogram parameters between p16 status [36] or between the more accurate HPV status [15]. This suggested independent prognostic value of ADC and HPV status. In contrast, HPV-positive tumors have a typical non-keratinizing morphology, with small central necrosis and large 


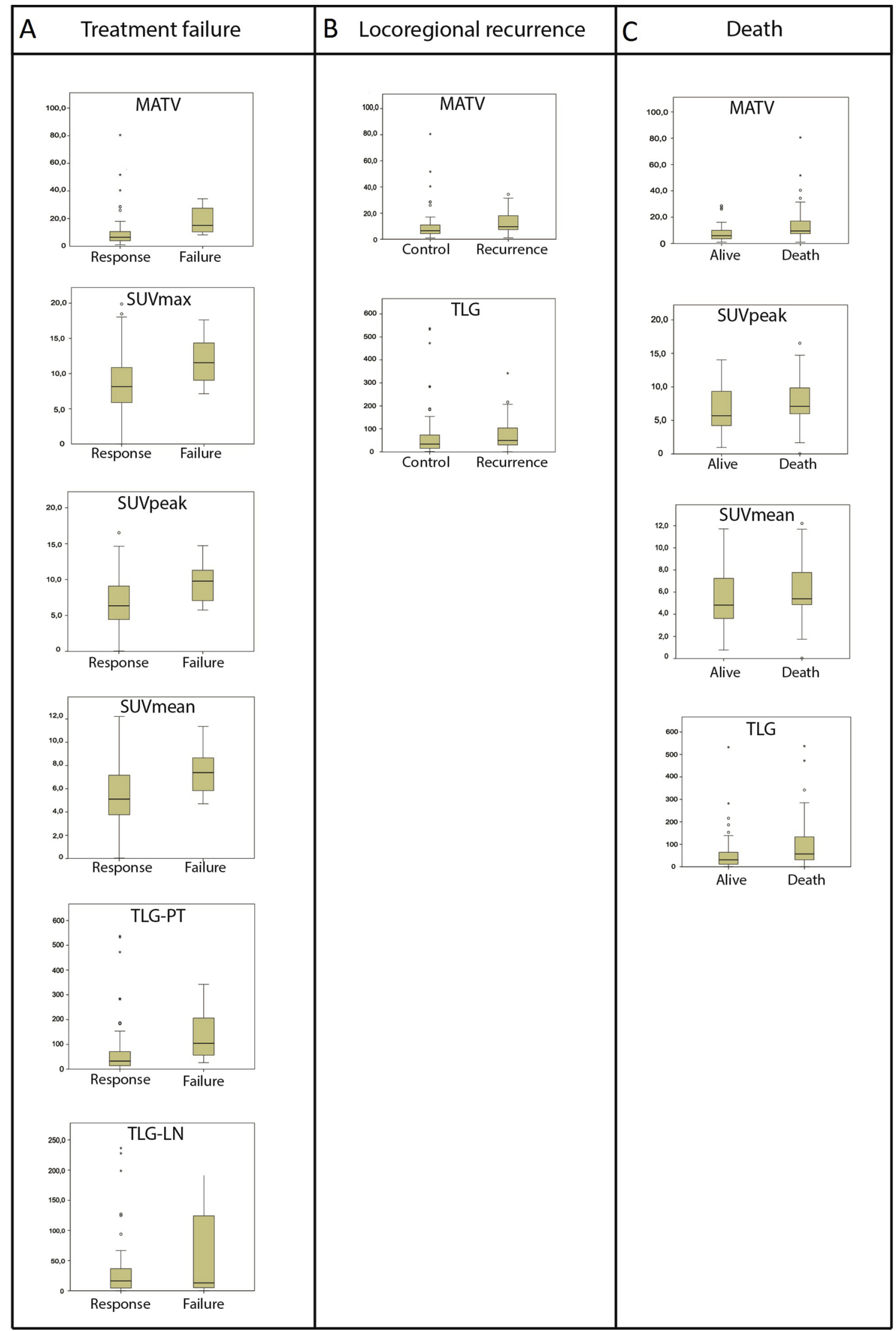

Fig. 4. Significant univariate primary tumor (PT) and lymph node metastasis (LN) ${ }^{18} \mathrm{~F}$-FDG-PET parameters predicting treatment failure, locoregional recurrence and

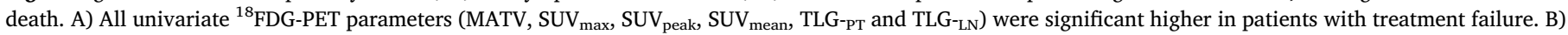
The MATV and TLG parameters were significant higher in patients with a locoregional recurrence. C) The MATV, SUV significantly higher in patients who died. However an overlap of ${ }^{18}$ F-FDG-PET-parameters values in patients who stayed alive and those who died, can be noticed. 
Table 4

Multivariate analysis of significant univariate parameters (marked green in Table 3) assessed per DWI and PET separately, corrected for TNM-stage and HPV-status. Hereafter, these significant multivariate parameters of the single modality section are combined in the 'modalities together' section to predict treatment failure, locoregional recurrence and death.

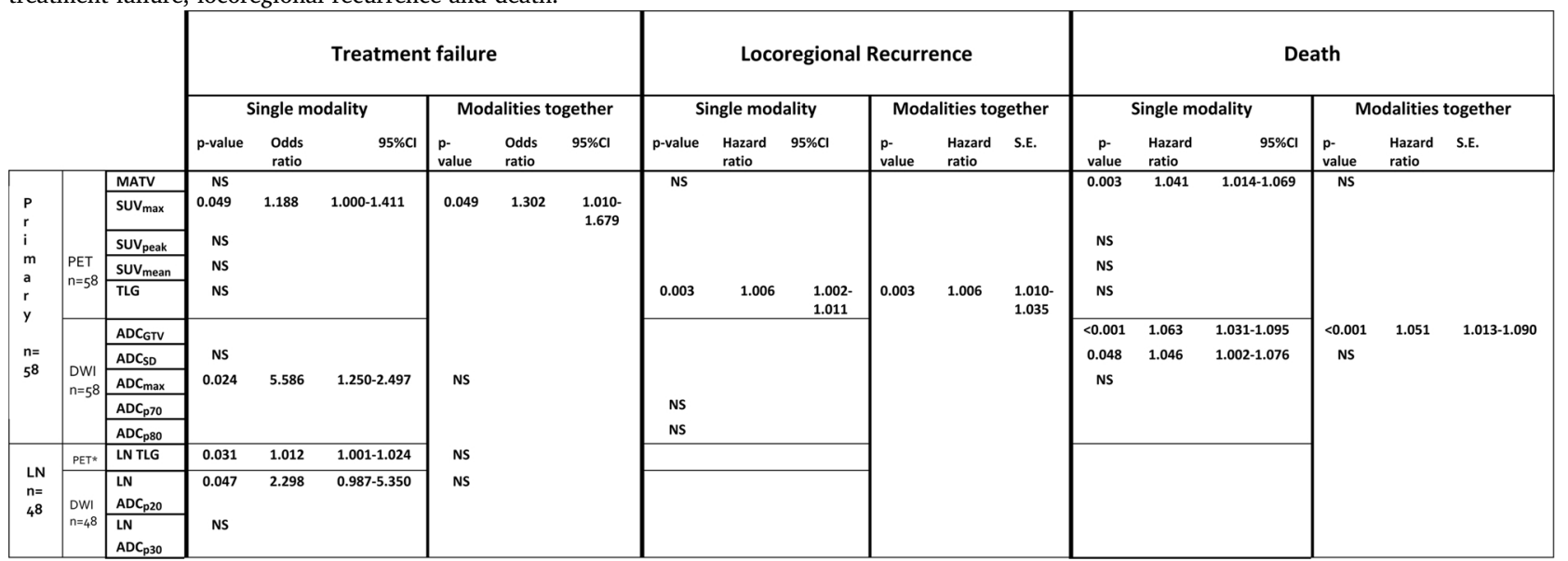

Abbreviations: NS: Not significant CI: confidence interval PET*: The lymph node metastasis analysis consisted of 48 patients.

amounts of infiltrating lymphocytes, low stromal volume (i.e low ADC), sufficient vascularization and, therefore, more responsive to (chemo) radiotherapy $[15,28,31]$.

Hypoxia may inhibit dividing tumor cells or lead to cell death (increased $\mathrm{ADC}$ ), due to insufficient oxygen supply, but it may directly induce tumoral progression (high FDG-uptake with reduced apoptosis, high production of VEGF, glycolic enzymes and signaling molecules $[12,38])$ with radioresistance. This however, was dependent on tumor grading with different relations between parenchyma, stroma and microvascular density [14,39]. Surov et al. [14] described that $\operatorname{SUV}_{\max }$ and $\mathrm{SUV}_{\text {mean }}$ were correlated with cellularity in advanced stage tumours (G3) and only HIF-1 $\alpha$ tended to correlate with FDG-uptake. HPVnegative tumours exhibit increased HIF1 $\alpha$-induced glucose metabolism as evidenced by increased glycolysis and proliferation (e.g. Ki 67), production of lactate and hypoxic microenvironment $[9,14]$. In contrast, HPV-positive cells effectively utilize mitochondrial respiration as evidenced by increased oxygen consumption [40-42] and low expression of HIF-1 $\alpha$ [36].We confirmed this hypothesis by finding significant

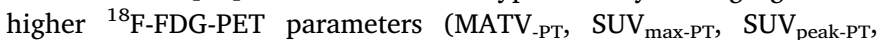
$\mathrm{SUV}_{\text {mean-PT }}$ and TLG-pt in univariate analysis) in HPV-negative than HPV-positive patients. This underlines the necessity for correction for HPV status in multivariate prognostic analysis.

The prediction of treatment failure was previously described performing single DWI $[16,20,43,44]$ or FDG-PET $[4,11,45]$. Nakajo et al. [5] compared both imaging techniques and found a similar predictive potential for ADC as for SUV predicting LRF in a small sample size. Limited data on the combination of imaging techniques was published. Kim et al. [46] found that volumetric MATV, TLG corrected by tumor cellularity $\left(\mathrm{ADC}_{\min }\right.$ and $\left.\mathrm{ADC}_{\text {mean }}\right)$ and were prognostic for $\mathrm{LR}$ [46]. However, their patient population underwent surgery, and sub-optimal delineation of only one imaging technique was performed. Although in advanced tumors $\mathrm{SUV}_{\max } / \mathrm{ADC}_{\min }, \mathrm{SUV}_{\max } / \mathrm{ADC}_{\text {mean }}$ and $\mathrm{TLG} / \mathrm{ADC}_{\min }$ correlated with cellularity, Ki67 and HIF-1a [47], no prognostic tests were performed. Chan et al. [21] found that a combination of PET heterogeneity (uniformity), DCE-MRI parameters and clinical risk factors was most predictive for LR and OS. However, in their study DWI was not applicable in the prognostic tests and HPV-status was lacking.

To our knowledge, the prediction of treatment failure and locoregional recurrence was not assessed before by combining PET and DWI together (including histogram parameters capturing tumor heterogeneity and clinical parameters including HPV-status) in a multivariate prognostic analysis and presented with a clinical applicable prediction model (Table 5). We showed that the combination of $\mathrm{ADC}_{\max }$ and
$\mathrm{SUV}_{\max }$ was more accurate than using a single imaging technique for predicting treatment failure (i.e. during the first 6 months after treatment). The prediction of locoregional recurrence showed TLG-pT as main prognostic parameter. This was in line with other studies, in which identification of necrosis or hypoxia and a higher glycolytic and increased tumor heterogeneity in HPV-negative tumors was predictive for treatment failure $[16,20]$. TLG has been suggested to reflect global metabolic activity in whole tumors better than MATV, as TLG represents both functional tumor burden and biological aggressiveness [48]. Regarding death, in this study only volumetric parameters (high MATV $_{\text {-PT }}$ and $\mathrm{ADC}_{\mathrm{GTV}-\mathrm{PT}}$ ) were found to be significantly predictive for death. This was confirmed in previous studies. However, high $\mathrm{SUV}_{\text {mean }}$ was also described as prognostic factor $[4,49]$.

The identification of predictive tumor characteristics predictive of resistance to (chemo)radiotherapy, such as a high intratumoral heterogeneity $\left(\mathrm{ADC}_{\mathrm{SD}}, \quad \mathrm{ADC}_{\max }, \mathrm{ADC}_{-\mathrm{P} 20-\mathrm{LN}}\right)$, tumor aggressiveness $\left(\mathrm{SUV}_{\max }\right)$ and a negative HPV-status, could help stratify risk groups, which might implicate tailored treatment (e.g., intensifying concurrent chemotherapy or offering alternative treatment options such as surgery as early possible to minimalize the side effects of ineffective chemoradiation). Patients with high $\mathrm{TLG}_{-\mathrm{PT}}$ and $\mathrm{ADC}_{\mathrm{GTV}-\mathrm{PT}}$ may be considered at high risk of locoregional recurrence and may benefit from intensifying post-treatment monitoring.

Our findings suggested that treatment failure prediction benefits from combining DWI with ${ }^{18}$ F-FDG-PET/CT imaging, by measuring the $\mathrm{ADC}_{\text {max-PT }}$ and $\mathrm{SUV}_{\text {max-PT }}$ (Table 5). However, the drawback of performing both imaging must be considered, e.g. a heavier burden for the patient and higher costs. Optimal cut-off values of $\mathrm{ADC}_{\text {max-PT }}$ and $\mathrm{SUV}_{\text {max-PT }}$ showed their diagnostic potential to considerably improve the prediction of treatment failure. In contrast, no additional value of combining imaging modalities was found for predicting LR and death (Fig. 5).

Some limitations must be acknowledged. First, ${ }^{18}$ F-FDG-PET/CT delineation bias could have occurred using a $50 \% \mathrm{SUV}_{\text {peak }}$ threshold, which excludes necrotic areas with low SUV [15]. This results in overall higher SUV and lower MATV, although it is more reproducible. Secondly, the maximum and minimum values of DWI and SUV parameters were single voxel dependent and therefore susceptible to noise. In this study, readers excluded voxels in areas of distortion or air, whereas the rest was considered characteristic for tumor phenotype. Furthermore, in this study the percentiles ranging from 10 to 90 were assessed, which are less effected by extreme values. Thirdly, the assessment of the largest LNs only could falsely ignore the prognostic adverse effect of 
Table 5

Positive (A) and negative (B) predictive value for treatment failure using both $\mathrm{ADC}_{\max }$ (horizontal) and $\mathrm{SUV}_{\text {max }}$ (vertical) with the most optimal cut-off values for each prevalence. A red colour marks a high predictive value for treatment failure.

A. Positive predictive value for treatment failure

\begin{tabular}{|c|c|c|c|c|c|}
\hline Prevalence & SUV $_{\text {max }}$ cut-off & Any $A D C_{\max }$ & $A D C_{\max }>1.927$ & $A D C_{\max }>2.236$ & $A D C_{\max }>2.528$ \\
\hline \multirow{4}{*}{0.10} & Any SUV max $_{\text {m }}$ & 0.10 & 0.20 & 0.36 & 0.43 \\
\hline & $>7.13$ & 0,13 & 0.26 & 0.44 & 0.50 \\
\hline & $>11.30$ & 0.19 & 0.34 & 0.54 & 0.61 \\
\hline & $>13.58$ & 0.28 & 0.47 & 0.66 & 0.72 \\
\hline \multirow{4}{*}{0.20} & Any SUV $V_{\max }$ & 0.20 & 0.36 & 0.56 & 0.63 \\
\hline & $>7.13$ & 0.25 & 0.44 & 0.64 & 0.70 \\
\hline & $>11.30$ & 0.34 & 0.54 & 0.73 & 0.78 \\
\hline & $>13.58$ & 0.46 & 0.66 & 0.82 & 0.85 \\
\hline \multirow{4}{*}{$0.30 *$} & Any SUV max $_{\text {max }}$ & 0.30 & 0.49 & 0.69 & 0.74 \\
\hline & $>7.13$ & 0.37 & 0.57 & 0.75 & 0.80 \\
\hline & $>11.30$ & 0.47 & 0.67 & 0.82 & 0.86 \\
\hline & $>13.58$ & 0.60 & 0.77 & 0.88 & 0.91 \\
\hline \multirow{4}{*}{0.40} & Any SUV max $_{\max }$ & 0.40 & 0.60 & 0.77 & 0.82 \\
\hline & $>7.13$ & 0.48 & 0.67 & 0.82 & 0.86 \\
\hline & $>11.30$ & 0.58 & 0.76 & 0.88 & 0.90 \\
\hline & $>13.58$ & 0.70 & 0.84 & 0.92 & 0.94 \\
\hline \multirow{4}{*}{0.50} & Any SUV max $_{\max }$ & 0.50 & 0.69 & 0.84 & 0.87 \\
\hline & $>7.13$ & 0.58 & 0.76 & 0.87 & 0.90 \\
\hline & $>11.30$ & 0.67 & 0.82 & 0.91 & 0.93 \\
\hline & $>13.58$ & 0.78 & 0.89 & 0.95 & 0.96 \\
\hline
\end{tabular}

B. Negative predictive value for treatment failure

\begin{tabular}{|c|c|c|c|c|c|}
\hline Prevalence & SUV $_{\max }$ cut-off & Any $A D C_{\max }$ & $A D C_{\max }<2.528$ & $\mathrm{ADC}_{\max }<2.236$ & $A D C_{\max }<1.927$ \\
\hline \multirow{4}{*}{0.10} & Any SUV max $_{\max }$ & 0.90 & 0.93 & 0.94 & 0.95 \\
\hline & $<13.58$ & 0.93 & 0.95 & 0.96 & 0.97 \\
\hline & $<11.30$ & 0.94 & 0.96 & 0.97 & 0.97 \\
\hline & $<7.13$ & 1.00 & 1.00 & 1.00 & 1.00 \\
\hline \multirow{4}{*}{0.20} & Any SUV $V_{\max }$ & 0.80 & 0.85 & 0.88 & 0.89 \\
\hline & $<13.58$ & 0.86 & 0.90 & 0.92 & 0.93 \\
\hline & $<11.30$ & 0.88 & 0.92 & 0.93 & 0.94 \\
\hline & $<7.13$ & 1.00 & 1.00 & 1.00 & 1.00 \\
\hline \multirow{4}{*}{$0.30 *$} & Any SUV max $_{\text {max }}$ & 0.70 & 0.77 & 0.81 & 0.83 \\
\hline & $<13.58$ & 0.79 & 0.84 & 0.87 & 0.89 \\
\hline & $<11.30$ & 0.82 & 0.86 & 0.89 & 0.90 \\
\hline & $<7.13$ & 1.00 & 1.00 & 1.00 & 1.00 \\
\hline \multirow{4}{*}{0.40} & Any $S_{U} V_{\max }$ & 0.60 & 0.68 & 0.73 & 0.76 \\
\hline & $<13.58$ & 0.70 & 0.77 & 0.81 & 0.84 \\
\hline & $<11.30$ & 0.74 & 0.80 & 0.84 & 0.86 \\
\hline & $<7.13$ & 1.00 & 1.00 & 1.00 & 1.00 \\
\hline \multirow{4}{*}{0.50} & Any SUV max $_{\text {max }}$ & 0.50 & 0.59 & 0.64 & 0.68 \\
\hline & $<13.58$ & 0.61 & 0.69 & 0.74 & 0.77 \\
\hline & $<11.30$ & 0.65 & 0.73 & 0.77 & 0.80 \\
\hline & $<7.13$ & 1.00 & 1.00 & 1.00 & 1.00 \\
\hline
\end{tabular}

*The prevalence of treatment failure in HNSCC in patients [1].

having multiple LN metastases. However, small LNs $(<5 \mathrm{~mm}$ ) cannot be assessed with sufficient accuracy on ${ }^{18}$ F-FDG-PET/CT [50]. Moreover, it is likely that the chance of eradication of small lymph node metastases is higher than larger LN. Therefore the prognosis might be determined by the largest lymph node metastases.

\section{Conclusion}

Both DWI and ${ }^{18}$ F-FDG PET/CT parameters appear to have predictive value for treatment failure, locoregional recurrence and death. Combining $\mathrm{SUV}_{\text {max-PT }}$ with $\mathrm{ADC}_{\text {max-PT }}$ improved treatment failure prediction compared to single parameter assessment. In contrast, no additional value of combining imaging modalities was found for predicting locoregional recurrence and death. Stratification of patients with DWI and ${ }^{18}$ F-FDG PET/CT parameters to predict favorable and unfavorable outcomes might help to tailor patient's individualized treatment.

\section{Role of the funding source}

This work was (partly) supported by grant 10-10400-98-14002 from the Netherlands Organisation for Health Research and Development. 
A Recurrence-free survival

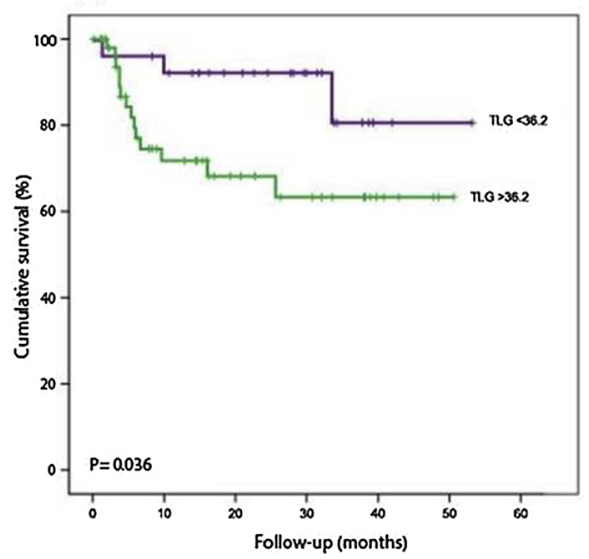

B

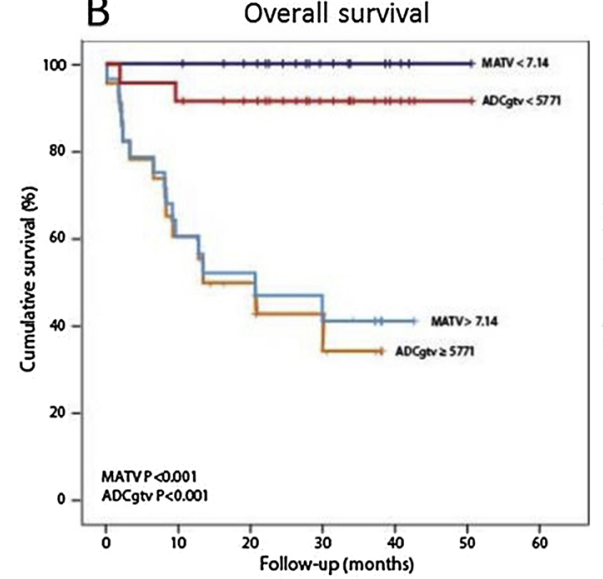

C

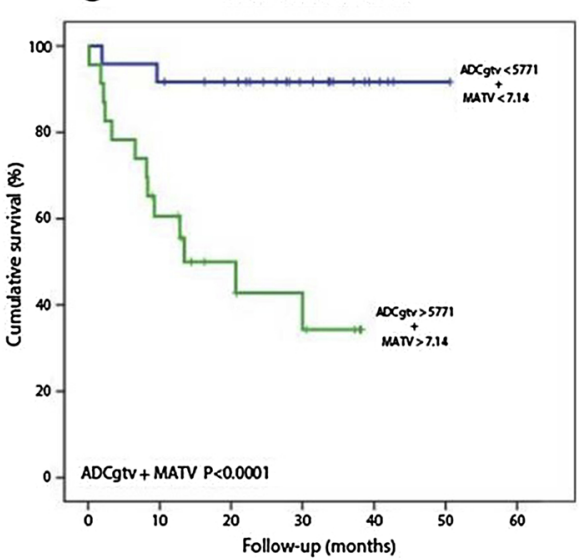

Fig. 5. A) Locoregional recurrence prognosis using TLG.pT with an optimal cut-off of 36.2, shows a significant Log-Rank test with a good differentiation on survival. B) Overall survival using MATV or $\mathrm{ADC}_{\mathrm{GTV}}$. (C) Overall survival predicted by a combination of $\mathrm{ADC}_{\mathrm{GTV}}$ and MATV showing no additional value to the use of the parameters separately (as is seen in B).

The funding source had no involvement in the collection, analysis and interpretation of data; in the writing of the report; and in the decision to submit the article for publication.

\section{Conflict of interest}

The authors declare no conflict of interest.

\section{Appendix A. Supplementary data}

Supplementary material related to this article can be found, in the online version, at doi:https://doi.org/10.1016/j.ejrad.2019.01.031.

\section{References}

[1] R.L. Siegel, K.D. Miller, A. Jemal, Cancer statistics, CA. Cancer J. Clin. 66 (1) (2016) 7-30.

[2] S. Semrau, F. Waldfahrer, L. M, Feasibility, toxicity, and efficacy of short induction chemotherapy of docetaxel plus cisplatin or carboplatin (TP) followed by concurrent chemoradio-therapy for organ preservation in advanced cancer of the hypopharynx, larynx, and base of tongue, Strahlentherapie und Onkologie: Organ der Deutschen Rontgengesellschaft 187 (1) (2011) 15-22 ... [et al].

[3] S.M.F. Chiesa, N. Tradati, L. Calabrese, G. Giugliano, M. Ansarin, J. Andrle, S. Zurrida, R. Orecchia, C. Scully, Surfing prognostic factors in head and neck cancer at the millennium, Oral Oncol. 35 (1999) 590-596.

[4] P. Xie, M. Li, 18F-FDG PET or PET-CT to evaluate prognosis for head and neck cancer: a meta-analysis, J. Cancer Res. Clin. Oncol. 137 (7) (2011) 1085-1093.

[5] M. Nakajo, M. Nakajo, Y. Kajiya, A. Tani, T. Kamiyama, R. Yonekura, Y. Fukukura, T. Matsuzaki, K. Nishimoto, M. Nomoto, C. Koriyama, FDG PET/CT and diffusionweighted imaging of head and neck squamous cell carcinoma: comparison of prognostic significance between primary tumor standardized uptake value and apparent diffusion coefficient, Clin. Nucl. Med. 37 (5) (2012) 475-480.

[6] F.D.K. Harriet, C. Thoeny, Ann D. King, Diffusion-weighted MR imaging in the head and neck, Radiology 263 (1) (2012) 19-32.

[7] N.A. Plaxton, D.C. Brandon, A.S. Corey, C.E. Harrison, A.T. Karagulle Kendi, R.K. Halkar, B.J. Barron, Characteristics and limitations of FDG PET/CT for imaging of squamous cell carcinoma of the head and neck: a comprehensive review of anatomy, metastatic pathways, and image findings, AJR. Am. J. Roentgenol. 205 (5) (2015) W519-31.

[8] H.J.M. Alexey Surov, Andreas Wienke, Correlation between apparent diffusion coefficient (ADC) and cellularity is different in several tumors: a meta-analysis, Oncotarget 8 (35) (2017) 59492-59499.

[9] A. Surov, H.J. Meyer, A. Wienke, Can imaging parameters provide information regarding histopathology in head and neck squamous cell carcinoma? A metaanalysis, Transl. Oncol. 11 (2) (2018) 498-503.

[10] J.P. Driessen, J. Caldas-Magalhaes, L.M. Janssen, F.A. Pameijer, N. Kooij, C.H. Terhaard, W. Grolman, M.E. Philippens, Diffusion-weighted Mr imaging in laryngeal and hypopharyngeal carcinoma: association between apparent diffusion coefficient and histologic findings, Radiology 272 (2) (2014) 456-463.

[11] M. Machtay, M. Natwa, J. Andrel, T. Hyslop, P.R. Anne, J. Lavarino, C.M. Intenzo, W. Keane, Pretreatment FDG-PET standardized uptake value as a prognostic factor for outcome in head and neck cancer, Head Neck 31 (2) (2009) 195-201.

[12] K.L. Tove, J. Grönroos, Karl-Ove Söderström, Pauliina Kronqvist, Jukka Laine, Olli Eskola, Tapio Viljanen, Reidar Grénman, Olof Solin, Heikki Minn, Hypoxia, blood flow and metabolism in squamouscell carcinoma of the head and neck: correlations between multiple immunohistochemical parameters and PET, BMC Cancer 14 (2014) 876.

[13] G.B. Rasmussen, I.R. Vogelius, J.H. Rasmussen, L. Schumaker, O. Ioffe, K. Cullen, B.M. Fischer, M.H. Therkildsen, L. Specht, S.M. Bentzen, Immunohistochemical biomarkers and FDG uptake on PET/CT in head and neck squamous cell carcinoma, Acta Oncol. (Stockholm, Sweden) 54 (9) (2015) 1408-1415.

[14] A. Surov, H.J. Meyer, A.K. Hohn, K. Winter, O. Sabri, S. Purz, Associations Between [(18)F]FDG-PET and Complex Histopathological Parameters Including Tumor Cell Count and Expression of KI 67, EGFR, VEGF, HIF-1alpha, and p53 in Head and Neck Squamous Cell Carcinoma, Molecular imaging and biology: MIB: the official publication of the Academy of Molecular Imaging, 2018.

[15] C.S. Schouten, P. de Graaf, E. Bloemena, B.I. Witte, B.J. Braakhuis, R.H. Brakenhoff, C.R. Leemans, J.A. Castelijns, R. de Bree, Quantitative diffusion-weighted MRI parameters and human papillomavirus status in oropharyngeal squamous cell carcinoma, AJNR. Am. J. Neuroradiol. 36 (4) (2015) 763-767.

[16] S. Chawla, S. Kim, L. Dougherty, S. Wang, L.A. Loevner, H. Quon, H. Poptani, Pretreatment diffusion-weighted and dynamic contrast-enhanced MRI for predic tion of local treatment response in squamous cell carcinomas of the head and neck, AJR. Am. J. Roentgenol. 200 (1) (2013) 35-43.

[17] G. Manca, E. Vanzi, D. Rubello, F. Giammarile, G. Grassetto, K.K. Wong, A.C. Perkins, P.M. Colletti, D. Volterrani, F-FDG PET/CT quantification in head and neck squamous cell cancer: principles, technical issues and clinical applications, Eur. J. Nucl. Med. Mol. Imaging 43 (7) (2016) 1360-1375.

[18] C.A. Krabbe, J. Pruim, A.M. Scholtens, J.L.N. Roodenburg, A.H. Brouwers, T.T. Ha Phan, A. Agool, P.U. Dijkstra, 18F-FDG PET in squamous cell carcinoma of the oral cavity and oropharynx: a study on inter- and intraobserver agreement, J. Oral Maxillofac. Surg. 68 (1) (2010) 21-27.

[19] S. Kim, L. Loevner, H. Quon, E. Sherman, G. Weinstein, A. Kilger, H. Poptani, Diffusion-weighted magnetic resonance imaging for predicting and detecting early response to chemoradiation therapy of squamous cell carcinomas of the head and neck, Clin. Cancer Res. 15 (3) (2009) 986-994.

[20] A. Srinivasan, T.L. Chenevert, B.A. Dwamena, A. Eisbruch, K. Watcharotone, J.D. Myles, S.K. Mukherji, Utility of pretreatment mean apparent diffusion coefficient and apparent diffusion coefficient histograms in prediction of outcome to chemoradiation in head and neck squamous cell carcinoma, J. Comput. Assisted Tomogr. 36 (1) (2012) 131-137.

[21] N.-M.C. Sheng-Chieh Chan, Chia-Hsun Hsieh, Shu-Hang Ng, Chien-Yu Lin, TzuChen Yen, Cheng-Lung Hsu, Hung-Ming Wan, Chun-Ta Liao, Kai-Ping Chang, JiunJie Wang, Multiparametric imaging using 18 parameters and functional MRI F-FDG PET/CT heterogeneity techniques: prognostic significance in patients with primary advanced oropharyngeal or hypopharyngeal squamous cell carcinoma treated withchemoradiotherapy, Oncotarget 8 (37) (2017) 62606-62621.

[22] M.C.F. Cysouw, G.M. Kramer, L.J. Schoonmade, R. Boellaard, H.C.W. de Vet, O.S. Hoekstra, Impact of partial-volume correction in oncological PET studies: a systematic review and meta-analysis, Eur. J. Nucl. Med. Mol. Imaging 44 (12) (2017) 2105-2116.

[23] J.B.R. Patrick, M. Bossuyt, David E. Bruns, M.D. Constantine, A. Gatsonis, Paul P. Glasziou, Les Irwig, G. Jeroen, David Lijmer, Moher, Drummond Rennie, C.W. Henrica, de Vet, Herbert Y. Kressel, Nader Rifai, Robert M. Golub, Douglas G. Altman, Lotty Hooft, Daniël A. Korevaar, Jérémie F. Cohen, An updated list of essential items for reporting diagnostic accuracy studies, Radiology 277 (3) (2015) $826-832$.

[24] R. Boellaard, R. Delgado-Bolton, W.J. Oyen, F. Giammarile, K. Tatsch, W. Eschner, F.J. Verzijlbergen, S.F. Barrington, L.C. Pike, W.A. Weber, S. Stroobants, D. Delbeke, K.J. Donohoe, S. Holbrook, M.M. Graham, G. Testanera, O.S. Hoekstra, J. Zijlstra, E. Visser, C.J. Hoekstra, J. Pruim, A. Willemsen, B. Arends, J. Kotzerke, A. Bockisch, T. Beyer, A. Chiti, B.J. Krause, M. European Association of Nuclear, 
FDG PET/CT: EANM procedure guidelines for tumour imaging: version 2.0, Eur. J. Nucl. Med. Mol. Imaging 42 (2) (2015) 328-354.

[25] F.H.Pv.V. Virginie Frings, Linda M. Velasquez, Wendy Hayes, Peter M. van de Ven, Otto S. Hoekstra, Ronald Boellaard, Repeatability of metabolically active tumor volume measurements with FDG PET/CT in advanced gastrointestinal malignancies: a multicenter study, Radiology 273 (2) (2014) 538-548.

[26] D.A. Schinagl, W.V. Vogel, A.L. Hoffmann, J.A. van Dalen, W.J. Oyen, J.H. Kaanders, Comparison of five segmentation tools for 18F-fluoro-deoxy-glucosepositron emission tomography-based target volume definition in head and neck cancer, Int. J. Radiat. Oncol. Biol. Phys. 69 (4) (2007) 1282-1289.

[27] G.S. Collins, J.B. Reitsma, D.G. Altman, K.G. Moons, Transparent reporting of a multivariable prediction model for individual prognosis or diagnosis (TRIPOD): the TRIPOD statement, Ann. Intern. Med. 162 (1) (2015) 55-63.

[28] J.P. Driessen, A.J. van Bemmel, P.M. van Kempen, L.M. Janssen, C.H. Terhaard, F.A. Pameijer, S.M. Willems, I. Stegeman, W. Grolman, M.E. Philippens, Correlation of human papillomavirus status with apparent diffusion coefficient of diffusionweighted MRI in head and neck squamous cell carcinomas, Head Neck 38 (2015) E613-E618.

[29] V. Paidpally, A. Chirindel, S. Lam, N. Agrawal, H. Quon, R.M. Subramaniam, FDGPET/CT imaging biomarkers in head and neck squamous cell carcinoma, Imaging Med. 4 (6) (2012) 633-647.

[30] Y.J. Choi, J.H. Lee, H.O. Kim, D.Y. Kim, R.G. Yoon, S.H. Cho, M.J. Koh, N. Kim, S.Y. Kim, J.H. Baek, Histogram analysis of apparent diffusion coefficients for occult tonsil cancer in patients with cervical nodal metastasis from an unknown primary site at presentation, Radiology 278 (1) (2016) 146-155.

[31] S.S. Foo, D.F. Abbott, N. Lawrentschuk, A.M. Scott, Functional imaging of intratumoral hypoxia, Mol. Imaging Biol. 6 (5) (2004) 291-305.

[32] S. Chawla, S. Kim, S. Wang, H. Poptani, Diffusion-weighted imaging in head and neck cancers, Future Oncol. (London, England) 5 (7) (2009) 959-975.

[33] T. de Perrot, V. Lenoir, M. Domingo Ayllon, N. Dulguerov, M. Pusztaszeri, M. Becker, Apparent diffusion coefficient histograms of human papillomaviruspositive and human papillomavirus-negative head and neck squamous cell carcinoma: assessment of tumor heterogeneity and comparison with histopathology, AJNR. Am. J. Neuroradiol. 38 (11) (2017) 2153-2610.

[34] M. Nakahira, N. Saito, H. Yamaguchi, K. Kuba, M. Sugasawa, Use of quantitative diffusion-weighted magnetic resonance imaging to predict human papilloma virus status in patients with oropharyngeal squamous cell carcinoma, Eur. Arch. OtoRhino-Laryngol. 271 (5) (2014) 1219-1225.

[35] M.W. Chan, K. Higgins, D. Enepekides, I. Poon, S.P. Symons, R. Moineddin, I. Weinreb, O. Shearkhani, A. Chen, J. Beelen, A. Chan, P.J. Maralani, Radiologic differences between human papillomavirus-related and human papillomavirus-unrelated oropharyngeal carcinoma on diffusion-weighted imaging, ORL 78 (6) (2016) 344-352.

[36] H.J. Meyer, L. Leifels, G. Hamerla, A.K. Höhn, A. Surov, ADC-histogram analysis in head and neck squamous cell carcinoma. Associations with different histopathological features including expression of EGFR, VEGF, HIF-1 $\alpha$, Her 2 and p53. A preliminary study, Magn. Reson. Imaging 54 (2018) 214-217.

[37] G. Omura, M. Ando, Y. Ebihara, Y. Saito, K. Kobayashi, O. Fukuoka, K. Akashi, M. Yoshida, T. Asakage, T. Yamasoba, The prognostic value of TP53 mutations in hypopharyngeal squamous cell carcinoma, BMC Cancer 17 (1) (2017) 898.

[38] A. Surov, P. Stumpp, H.J. Meyer, M. Gawlitza, A.K. Hohn, A. Boehm, O. Sabri, T. Kahn, S. Purz, Simultaneous (18)F-FDG-PET/MRI: associations between diffusion, glucose metabolism and histopathological parameters in patients with head and neck squamous cell carcinoma, Oral Oncol. 58 (2016) 14-20.

[39] L. Leifels, S. Purz, P. Stumpp, S. Schob, H.J. Meyer, T. Kahn, O. Sabri, A. Surov, Associations between (18)F-FDG-PET, DWI, and DCE parameters in patients with head and neck squamous cell carcinoma depend on tumor grading, Contrast Media Mol. Imaging 2017 (2017) 1-8.

[40] A.J.N. Young-Suk Jung, Wei Huang, Seema Sethi, Michael Snyder, Wael Sakr, Gregory Dyson, Maik Hüttemann, Icksoo Lee, Rouba Ali-Fehmi, Franceschi Silvia, Linda Struijk, Harold E. Kim, Ikuko Kato, Hyeong-Reh Choi Kim, HPV-associated differential regulation of tumor metabolism in oropharyngeal head and neck cancer, Oncotarget 8 (31) (2017) 51530-51541.

[41] C.S. Schouten, S. Hakim, R. Boellaard, E. Bloemena, P.A. Doornaert, B.I. Witte, B.J. Braakhuis, R.H. Brakenhoff, C.R. Leemans, O.S. Hoekstra, R. de Bree, Interaction of quantitative (18)F-FDG-PET-CT imaging parameters and human papillomavirus status in oropharyngeal squamous cell carcinoma, Head Neck 38 (4) (2016) 529-535.

[42] J.A.O.D. Paul Burgman, John L. Humm, C. Clifton Ling, Hypoxia-induced increase in FDG uptake in MCF7 cells, J. Nucl. Med. 42 (2001) 170-175.

[43] S. Kim, L.A. Loevner, H. Quon, A. Kilger, E. Sherman, G. Weinstein, A. Chalian, H. Poptani, Prediction of response to chemoradiation therapy in squamous cell carcinomas of the head and neck using dynamic contrast-enhanced MR imaging, AJNR. Am. J. Neuroradiol. 31 (2) (2010) 262-268.

[44] A.D. King, F.K. Mo, K.H. Yu, D.K. Yeung, H. Zhou, K.S. Bhatia, G.M. Tse, A.C. Vlantis, J.K. Wong, A.T. Ahuja, Squamous cell carcinoma of the head and neck: diffusion-weighted MR imaging for prediction and monitoring of treatment response, Eur. Radiol. 20 (9) (2010) 2213-2220.

[45] B. Zhang, F. Nie, B. Jin, Q. Meng, P. Dong, Pretreatment tumor standardized uptake value as a prognostic factor in primary head and neck squamous cell carcinoma, Mol. Clin. Oncol. 3 (2) (2015) 392-396.

[46] Y.I. Kim, G.J. Cheon, S.Y. Kang, J.C. Paeng, K.W. Kang, D.S. Lee, J.K. Chung, Prognostic value of simultaneous (18)F-FDG PET/MRI using a combination of metabolo-volumetric parameters and apparent diffusion coefficient in treated head and neck cancer, EJNMMI Res. 8 (1) (2018) 2.

[47] A. Surov, H.J. Meyer, A.K. Hohn, O. Sabri, S. Purz, Combined metabolo-volumetric parameters of (18)F-FDG-PET and MRI can predict tumor cellularity, Ki67 level and expression of HIF 1alpha in head and neck squamous cell carcinoma: a pilot study, Transl. Oncol. 12 (1) (2019) 8-14.

[48] Y.E. Steven, M. Larson, Timothy Akhurst, Madhu Mazumdar, Homer A. Macapinlac, Ronald D. Finn, Cecille Casilla, M.S. Melissa Fazzari, Neil Srivastava, Henry W.D. Yeung, John L. Humm, Jose Guillem, Robert Downey, Martin Karpeh, Alfred E. Cohen, Robert Ginsberg, Tumor treatment response based on visual and quantitative changes in global tumor glycolysis using PET-FDG imaging: the visual response score and the change in total lesion glycolysis, Clin. Positron Imaging 2 (3) (1999) 159-171.

[49] S.W. Chen, T.C. Hsieh, K.Y. Yen, J.A. Liang, C.H. Kao, Pretreatment (18)F-FDG PET/ CT in whole-body total lesion glycolysis to predict survival in patients with pharyngeal cancer treated with definitive radiotherapy, Clin. Nucl. Med. 39 (5) (2014) e296-300.

[50] R.L. Wahl, H. Jacene, Y. Kasamon, M.A. Lodge, From RECIST to PERCIST: evolving considerations for PET response criteria in solid tumors, J. Nucl. Med. 50 (5) (2009) 122S-150S. 